\title{
Inter- and intraindustrial Job-to-Job Flows. A Linkage Analysis of Regional Vacancy Chains in Austria.
}

\author{
CHRISTINE M. AUMAYR ${ }^{* \dagger}$ \\ Joanneum Research, Institute of Technology and Regional Policy
}

\begin{abstract}
Nine Austrian NUTS 2 inter- and intraindustrial job-to-job worker flows for 33 industries are analysed by means of input-output techniques, with these job-to-job flows being an intermediate input in the production of filled vacancies. A new dataset on individual labour market episodes allows for the tracing of individual careers. A linkage analysis of the Leontief multiplier shows that business services, wholesale\&retail and the metalindustry are 'key' industries in for- and backwarding employment, whereas construction and tourism exert an impact on other regional industries by absorbing workers upon aggregate external shocks. These findings can be incorporated in industrial employment forecasts or utilized in regional labour market impact studies.
\end{abstract}

Keywords: worker flows, sectoral labour reallocation, regional labour markets, vacancy chains, vacancy chain table, linkage analysis, Leontief multiplier, impact evaluation.

JEL Classifications: J60, J62, R15, R23, C67

\section{Introduction}

Daily business of regional impact studies on the labour market effects of regional investments or job programmes and the closing or opening of bigger firms together with daily business of industrially disaggregate employment forecasts have opened the gate to the following research questions: What are the regional labour market impacts of industrial demand shocks? Does the involved labour force unfold further impacts in other industries?

This paper presents some intermediate steps and results in answering these questions. The particular interest of this paper lies on the question how to capture not only 'first round' effects of observed labour mobility, but also induced 'second wave moves' are taken into account because of vacancies being refilled after labour reallocation. It thereby focuses on the worker

*This paper is part of the project 'DEMEC' for which co-funding is gratefully obtained by the Jubilaeumsfonds of the Austrian National Bank OeNB and the Federal Ministry of Labour, Social Affairs and Consumer Protection. The author wants to thank Andreas Buzek, Dominik Janisch, Raimund Kurzmann and Michael Steiner as well as an anonymous referee and the discussants of the first GLUNLAB research seminar in Thessaloniki 2008 and of the winter seminar of the Gesellschaft fuer Regionalforschung, Igls 2009.

${ }^{\dagger}$ Tel. +353 851761086, Institute of Technology and Regional Policy, Elisabethstr. 20, $8010 \mathrm{Graz}$

(C) 2010 Christine M. Aumayr. Licenced under the Creative Commons Attribution-Noncommercial 3.0 Licence (http://creativecommons.org/licenses/by-nc/3.0/). Available at http://rofea.org. 
mobility in and between industries and exploratively tries to analyze those second wave moves which may be induced by direct employment-to-employment (E-E) flows.

Why are these questions of importance? And which points should labour market impact evaluation studies take into account? The past two decades have witnessed a growing interest in and a growing body of literature ${ }^{1}$ on labour market flows, both from the worker and the job perspective. The fact that high levels of separations continue in expanding firms and hiring goes on in shrinking establishments focuses the view on worker flows and their determinants. Empirical studies have found a large excess of labour reallocation over job reallocation: Burgess, Lane and Stevens (2000) among others estimate these levels of 'churning' which amount to approximately $2 / 3$ of total worker flows. Furthermore, both job and worker flows have been discussed regarding their variation over regions, industries and the business cycle. Worker flows may originate from pecuniary and non-pecuniary [(Akerlof, Rose and Yellen 1988)] motivated searches for new positions. In an environment of underemployment (i.e. with respect to qualification), the extent to which these flows originate from formerly employed is increased and in such an environment, every observed move incorporates a potential (regional) welfare gain, being equal to the (wage - or job-satisfaction) differential. Persky, Felsenstein and Carlson (2004) have discussed extensively the implications of these concepts for regional/local impact studies and presented a coherent model of how to value accurately the regional impacts of job creating programmes by taking into account the endogenously driven impact of direct E-E moves. They propose the 'vacancy chain approach' (VCA) as an instrument for modelling these dynamics. The currently widely used matching function approach - in which a pool of job-searchers is matched to a pool of vacancies - does not account for E-E moves and implied interlinkages [(Mortensen and Pissarides 1992), (Mortensen and Pissarides 1994)] and is furthermore applied seldomly at an industrially disaggregate level. In contrast, the VCA allows jobs to be handed over from person to person, hence to model explicitly E-E flows and second wave moves as a reaction to exogenous shocks. Here, the VCA is handled by input-output analytic techniques. In this regard, the findings on the behaviour of worker flows are related to traditional input-output analysis and yield 'vertical' labour market multipliers paralleling the traditional 'horizontal' multipliers on goods-markets. All vertical multiplier effects can be interpreted as net gains and the effects of job creating programmes can 'trickle down' to other strata by the endogenous mechanism of vacant positions being handed over interpersonally (Persky et al. 2004), (Persky and Felsenstein 2008).

Up to now, empirical applications of this concept to regional labour markets have been very scarce, as this approach warrants vast information on inter- and intra -regional and -industrial worker flows beside the usual labour market flows between different labour market states. With

${ }^{1}$ i.e. (Blanchard and Diamond 1990), (Blanchard and Diamond 1992), (Eriksson and Pehkonen 1998), (Decressin and Fatas 1995), (Davis and Haltiwanger 1989), (Davis and Haltiwanger 1992), (Butter and van Dijk 1998), (Garibaldi 2000), (Gomez-Salvador, Messina and Vallanti 2004), (Pissarides 2000) 
a fairly new administrative career-monitoring dataset of non-overlapping individual labour market episodes of 'all' insured and co-insured Austrian people, the tracing of worker flows within and across regions, industries and detailed labour market states has become available for the first time. This paper presents results on establishing and analyzing 9 separate vacancy chain tables of the Austrian Bundeslaender (NUTS 2 regions) by means of a linkage analysis of the Leontief multiplier matrix of vacancy chains. Industrial backward linkages - or the column sum of the Leontief multiplier matrix - give the length of the multiplier when vacancies are generated in one industry. These multipliers are the backbone for further impact analytic exercises in which regional welfare gains could be calculated potentially. However, the present paper does not go that far, but further focuses on an analysis of interindustrial linkages. The analysis generates a 'systemic' view of the labour markets and examines the industry's specific 'role' in forand backwarding employment opportunities and its reaction to specific or aggregate external shocks. Knowledge of these interlinkages can be incorporated in industrially disaggregate employment forecasts. What remains to be done, is to link the observed patterns with data on wage differentials or reservation wages in order to evaluate regional welfare impacts of programmes. These questions however are left for future research.

The paper is organized as follows: Section 2 gives a brief overview of the job and worker flow literature, followed by an overview of the vacancy chain literature and its application in regional labour market research. Section 3 describes the utilized new database which allows for the career tracing of workers by industries and regions. In section 4 the process of establishing regional vacancy chain tables for the 9 Austrian regions is discussed in relation to the database. Section 5 presents the formal Leontief model as well as the linkage measures applied, while section 6 provides the empirical results of the linkage analysis. Section 7 summarizes the findings and gives an outlook to further aspects worth considering.

\section{Worker Flows and Vacancy Chains in Regional Labour Markets}

\subsection{Worker and Job Flows}

Labour markets are generally characterized by high mobility dynamics, a fact which is mostly hidden behind period-to-period growth observations of stock variables such as the number of persons in dependent employment. A vast labour market literature of the past decade has focused on the theoretical and empirical aspects of 'worker flows' ${ }^{2}$ and 'job flows'" in the labour

\footnotetext{
${ }^{2}$ For worker flows see for example Blanchard and Diamond (1990), Blanchard and Diamond (1992), Eriksson and Pehkonen (1998), Decressin and Fatas (1995)

${ }^{3}$ For job flows on the other hand see for example Davis and Haltiwanger (1989), Davis and Haltiwanger (1992), Butter and van Dijk (1998), Garibaldi (2000), Gomez-Salvador et al. (2004), Mortensen and Pissarides (1992), Mortensen and Pissarides (1994), Pissarides (2000)
} 
AUMAYR Inter- and intraindustrial Job-to-Job Flows

marked. ${ }^{4}$ Job flows might come into being on the plant level by new foundations and the expansion of firms, or by the closing down or shrinking of establishments. Worker flows may arise from job flows ${ }^{5}$, but might also originate from workers decisions such as migration, maternity leaves, the response to higher wage offers, the search for positions which yield a higher labour satisfaction (Akerlof et al. 1988) or from firm originated decisions to opt for more profitable matches (in the sense of Pissarides's (2000) matching model). Furthermore, the role of worker flows in generating intra- or interindustrial knowledge spillovers have been subject to discussion [i.e.: (Shankar and Ghosh 2005), (Moen 2004), (Moen 2005)].

The coexistence of both worker or job in- and outflows over the business cycle and the fact that worker and job flows do not coincide is generally assumed to be explained by worker and firm heterogeneity. In this paper, this view is extended to regional heterogeneity ${ }^{6}$.

Among others, regions may be different with respect to several economic characteristics such as average plant size, sectoral/industrial specialization ${ }^{7}$, industry specific qualificatory requirements, different degrees of openness or differences in composition or mobility of the regional labour force ${ }^{8}$. All of these factors may influence or determine how aggregate or industrial demand shocks are transmitted through the 'whole' regional labour market or give rise to varying extents of interregional (knowledge) spillovers.

\subsection{The vacancy chain approach}

In order to capture these inter- and intra-regional as well as industrial flows, this paper will make use of the so called vacancy chain approach (VCA). The VCA has been applied in many fields of research where resources can be handed over between mobile entities. In its essence it is a relatively 'mechanistic' view of a system of observed flows between different states or

${ }^{4}$ See for example Boeckerman, Haemaelaeinen and Maliranta (2002), Burgess, Lane and Stevens (1995) and Burgess, Lane and Stevens (2001) for a combination of both.

${ }^{5}$ For the Dutch manufacturing sector Gautier and Broersma (2001) report that only about one third of worker flows is driven by job creation and destruction: While employment inflows are to a large part driven by job creation, employment outflows are not driven by job destruction. Davis and Haltiwanger (1992) do see (U.S.) worker flows originating mainly from job flows, or the 'reshuffling of employment opportunities across plants', but stress that this view neglects induced second wave moves.

${ }^{6}$ Eberts and Montgomery (1995) for the U.S. and Boeckerman et al. (2002) for Finnish regions have found that employment inflows/job creation are rather explained by regional variation, whereas employment outflows/job destruction are determined by cyclical variation.

${ }^{7}$ Contini and Revelli (1997) report that job reallocation is negatively linked to capital intensity, that is higher in services and lower in manufacturing. Furthermore it is higher in smaller and young firms and often, but not necessarily higher in innovative industries.

${ }^{8}$ Blanchard and Diamond (1990) distinguish between primary and secondary workers, heterogeneous with respect to sex and age, whose behaviour extends to the business cycle: Secondary workers (younger, older and women) quit more often, are laid off first and search less when non-employed than do primary workers (mature, 'head of household'). 
resources, which allows for an analysis or forcasting of mobility-patterns. ${ }^{9}$

Starting from the observation that job-to-job changes without intermediate unemployment spell were a relevant empirical phenomenon, the vacancy chain approach (VCA) entered into the labour economic literature with papers by Akerlof et al. (1988) ${ }^{10}$ and Contini and Revelli (1987), earlier already by Emmi (1985) from a regional welfare economic point of view. In contrast to the non-interlinkage view of the aggregate matching function, vacancy chain type models describe the matching process as an interlinked system of worker or vacancy flows. Vacancy flows are just the opposite of worker flows (which are identified by matches and quits), so vacancies are only identified ex post when matches have occured. Jobs are a resource which can be handed over to mobile persons. Each job-quit for whatever demographic reason ${ }^{11}$ (i.e. outmigration, maternity leave...) can start a 'chain' of further mobility. This chain continues to grow as long as the vacant job positions are filled by people leaving a further vacant position behind and is terminated when people not leaving a vacancy behind are taking over a position. These might be regional immigrants, formerly unemployed or reentrants into the labour market. Accordingly chains are initiated by demographic or worker flow reasons through outmigration, unemployment or the exit of labour force. On the other hand, chains may also start and terminate because of economic reasons which are job creating events such as the expansion/decline of establishments or the foundation of new firms. In this sense, the VCA allows for a combined view of worker and job mobility. Its ability to explicitly account for intersectoral/regional linkages and linkages with other labour market states is a main advantage of the VCA over the widely used concept of the aggregate matching function of the type ( $m=f(u, v)$ ). In a multiregional context it would furthermore be related to the field of spatial econometrics [(Anselin 1988)] which tries to tackle estimation problems originating from spatial spillovers. The VCA explicitely models these interlinkages, but is therefore highly data-consuming. Moreover, the utilization of I-O techniques has always been subject to criticism, basically because of the linear-limitational production technology and the lack of inference methods. Whereas I-O models are nowadays still a popular working horse in regional economics for applied modelling of interregional and interindustrial linkages on good markets, regional labour markets and the

\footnotetext{
${ }^{9}$ In his seminal papers of the early 1970s White [(White 1970b), (White 1970a) and (White 1971)] introduced Input-Output and Markov-models as tools for analyzing vacancy chains. Thereafter the VCA found it's entrance into sociologic research fields (organizational demography, internal labour markets [eg. (Pinfield 1997), (Chase 1991)], the analysis of housing markets [(Emmi and Magnusson 1994), (Emmi and Magnusson 1995), (Emmi 1984)] and was even applied in a model of matching hermit crabs with shells (Chase, Weissburg and Dewitt 1988). Further theoretic contributions were made by Blum, Roth and Rothblum (1997) who modeled vacancy chains by means of game-theoretic two-sided matching models.

${ }^{10}$ Akerlof et al. (1988) argued that 'job satisfaction' is the main driver between job-to-job changes. The absence of job satifaction leads even employed workers to search for a new and more satisfying positions.

${ }^{11}$ Emmi (1985) distinguishes between demographic and economic reasons, which can be identified as the job vs. worker terminology of the labour market literature.
} 
AUMAYR Inter- and intraindustrial Job-to-Job Flows

related worker flows have - up to now - been very seldomly subject to analysis from this point of view. Probably the main reason is to be found in the high data requirements on worker flows between different strata. In recent contributions by an international team of regional economists [(Felsenstein, Persky and Carlson 2002), (Persky et al. 2004), (Persky and Felsenstein 2008), (Felsenstein and Persky 2006)] a relaunch of positioning the VCA in regional labour market analysis has begun, but is still pending further contributions. In a regional context, Persky et al. (2004) argue that the traditional vertical linkages between industries and the resulting multiplier effects are accompanied by horizontal vacancy chain linkages on the labour market. In heterogeneous regional labour markets, industry-wise job creation or destruction will therefore unfold different dynamics and a different impact on the regional labour market, depending on the hierarchic level of the position where the vacancy chain starts, ${ }^{12}$ the question whether the required staff can be hired in the region, or needs to be attracted from outside and the extent to which the required workforce is attracted from other regional firms or from the non-employed regional workforce. For a detailed discussion on the application of vacancy chain type models in the regional context, see Persky and Felsenstein (2008) and Felsenstein and Persky (2006).

\section{Data: Individual career monitoring data}

The Austrian AMS-BMWA Labour Market Research Databbase (LMDB) is a mutual project of the PES Austria ( $A M S$, the public employment service) and the Austrian Ministry for Labour, Social Affairs and Consumerism (BMASK) (AMS and BMWA 2007). The LMDB combines administrative insurance information of the $H V S V^{13}$, the Main Association of the Austrian Social Security Institutions, on all insured and co-insured people (including non-employed states) with unemployment states as registered by the PES Austria. Data utilized here are taken from the career monitoring section which incorporates 'all' insured and co-insured people with their unique and non-overlapping ${ }^{14}$ labour market episode for each day. Table 2 at page 103 in the appendix lists the labour market states available in the database. The data includes qualities such as sex, age, academic degree, nationality, migratory background, estimated monthly income as registered by the HVSV, region of work and living, qualification, health problems and responsibilty for children and employer information such as size and industry.

Being based on observed individual labour market episodes extensive manipulations had to

\footnotetext{
${ }^{12}$ The positions might be ordered i.e. by industry, qualification, professions or wage groups

${ }^{13}$ Hauptverband der Sozialversicherungstraeger

${ }^{14}$ This is achieved by the application of a dominance-rule system in case of overlapping episodes, which is generally based on a subsistence rule: dependent employment is generally ranked higher than selfemployment and states out of labour force with assured incomes (pensions, maternity-leave pay etc.), followed by registered unemployment, marginal employment and other $O L F$ status without income. Additionally, short work episodes of 'fragmented' employment at the same employer were summarized in the database as 'fragmented' employment, when the working episodes were shorter than 32 days and the time of interruption was shorter than 28 days.
} 
be undertaken at the micro-level to generate the observed aggregate flows. In particular, the re-definition of figures with respect to cut-off dates and the identification of future episodes were necessary tasks to ensure the accounting identity ${ }^{15}$ required for the establishment of the tables. Further details on the data will be discussed in the next section which focuses on the establishment of the vacancy chain tables.

\section{Establishing Austrian Regional Vacancy Chain Tables}

In the context of this research paper, vacancy chain tables are established separately for 9 NUTS 2 regions for the period 2004 at a level of 332 -digit OENACE aggregates (industries $n=1 \ldots 33$ ). The basic component of a vacancy model are enlarged origin-destination matrices ${ }^{16}$ as depicted in figure 1. These matrices summarize observed per period person flows between different labour market states as well as regions and are set up on an accounting identity similar to inputoutput tables. While input-output tables summarize inter- and intraindustrial flows of goods, vacancy chain tables embody information on worker flows from and to different job positions into and out of the system of dependent employment in a given period of time. The flow of a person into the other direction gives the so called vacancy flow: When a person leaves a position in industry $i$ a vacancy is created there. This vacancy can be handed over to another industry $j$, when a formerly industry $j$ worker takes over the first vacancy. Note here, that the whole information in these tables is based on information on worker flows and the workers' effective matches or separations 'ex post'. The table does not incorporate information on unfilled or posted vacancies. Vacancies are only observed 'ex post' once they have been filled.

The core of the vacancy chain table is the vacancy transfer or mobility matrix $N^{T}=M$ (drawn here both from the vacancy or the workers' perspective) in which the sum of all inter and intra-industrial E-E moves without intermediate unemployment or other spells is summarized for the particular period $t$ in region $r$. The entries of the transfer matrix are read - line by line - as follows: $n_{11}$ vacancies move from industry 1 to somewhere else in the same industry, whereas $n_{1 n}$ vacancies move from industry 1 to industry $n$ which is equivalent to stating that $n_{1 n}$ workers have moved from industry $n$ to 1 . With reference to the LMDB data the mobility matrix is set up by counting all per period moves of workers from dependent employment to dependent employment (E-E), from one employer to another without a single day of another spell in between. Self-dependent employment is excluded from the mobility matrix as no sectoral information is available for this status. Worker outflows from dependent employment are summarized in the vectors $o_{1}$ and $o_{2}$. The first vector comprises all intraregional outflows from

\footnotetext{
${ }^{15}$ Still pending to be done is the question of how to deal with 'administrative' reclassification of firms as far as it concerns industries.

${ }^{16}$ Notation and accounting design here is based on the works by Emmi and Magnusson. [(Emmi and Magnusson 1993), (Emmi 1984), (Emmi 1985), (Emmi 1986), (Emmi and Magnusson 1994) (Emmi and Magnusson 1995)]
} 
AUMAYR Inter- and intraindustrial Job-to-Job Flows

Figure 1: Vacancy Chain Table with Persons or Vacancies as Mobile Entities, Gross Flows, based on Emmi/Magnusson (1994)

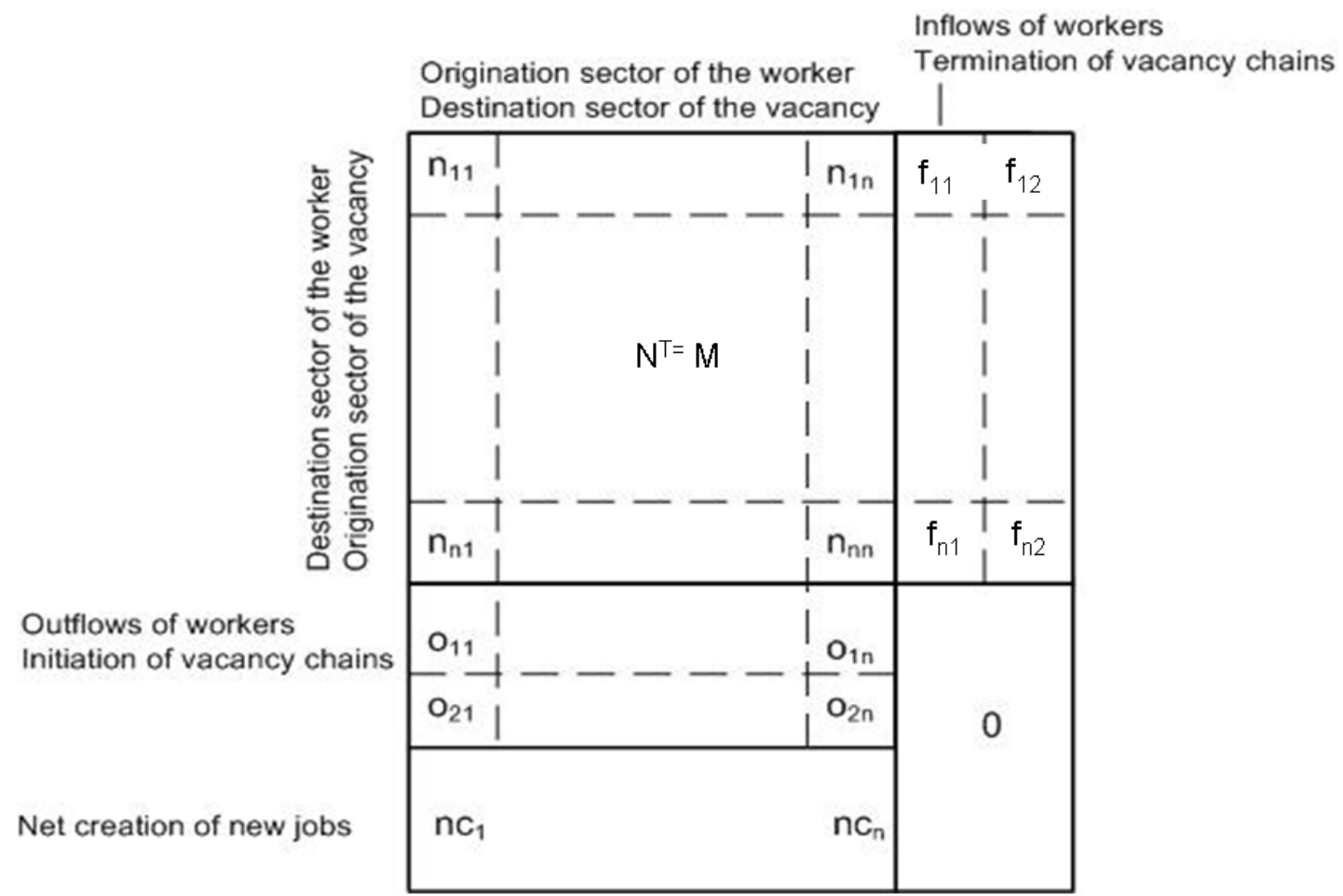

dependent employment into all other labour market states such as self dependent employment, maternity leaves, unemployment, etc. ${ }^{17}$ The second one summarizes interregional outflows irrespective of the labour market status in the destination region. Vectors $f_{1}$ and $f_{2}$ accordingly summarize intraregional worker inflows from other labour market states into dependent employment and interregional inflows irrespective of past labour market status. To complete the column-wise view, a total amount of $n c_{1}$ net new work-positions is created or terminated in industry 1 in period $t$ which is simply the net stock change of employment per industry during the period. All schedules are based on the accounting identity of the per period net creation of regional new dependent employment being equal to the sum of all inflows less the sum of all outflows in each industry. In a particular region $r$ the net creation of new employment $n c_{t, n}$ in period $t$ and sector $i, j$ is given by

$$
n c_{i}^{t}=e_{i}^{t}-e_{i}^{t-1}=i n_{i}^{t}-o u t_{i}^{t}=\left(f_{i}^{t}+\sum_{j=1}^{n} n_{i j}^{t}\right)-\left(o_{j=i}^{t}+\sum_{i=1}^{n} n_{i(j=i)}^{t}\right)
$$

\footnotetext{
${ }^{17}$ Compare Table 2 in the appendix for a detailed list of the available labour market status.
} 
where $e_{n}^{t}$ refers to the stock of industrial employment at the end of period $t, i n_{t}$ and out $_{t}$ are the respective per period in- and outflows of workers including both: the E-E moves in the mobility matrix, viz. their row and column sums and the employment in- and outflows $f_{i}=f_{1 i}+f_{2 i}$ and $o_{j}=o_{1 j}+o_{2 j}$ as described above during period $t=1^{18}$.

\section{The Leontief Multiplier and Total Linkage Measures}

Applied to vacancy chains a Leontief model can be utilized to evaluate number and industrial composition of net new jobs needed in order to satisfy an exogenously given amount of new entrants by industry. The following formal model is based on Emmi (1985) and Emmi and Magnusson (1994) and refers to gross flows and vacancies as mobile entities. Keeping the above described vacancy chain tables in mind, the definitorial identity of equation 2 - now in matrix notation - serves as starting point. The row sum $s$ over the enlarged matrix gives the gross number of persons which enter each industry by period. This equals the sum of all interindustrial flows to industry $i$ plus the number of new entrants of workers $f$ from other regions or labour market states.

$$
s=N^{T} 1+f
$$

where 1 represents a unity vector.

Under the condition of a certain stability of the transfer matrix ${ }^{19} N^{T}$, this definitorial equation can be transfered into a formal model.

The basis of the analytical model is the matrix of transfer probabilities $T$ whose elements $t_{i j}$ indicate the probability that a vacancy observed in industry $j$ comes from industry $i$.

$$
s=T s+f
$$

Here, these probabilities are simply ${ }^{20}$ derived as the fraction of vacancy moves from one industry to another in relation to total moves out of the industry. Each element $n_{i j}$ of the transfer

\footnotetext{
${ }^{18}$ Carrying over to 'ordinary' input-output analysis the value of $n c_{i}$ corresponds to industrial gross value added. It is so to say the amount of additional jobs not used up in the process of moves, but readily available to serve an additional amount of workers (irrespective of their origin). Accordingly, the row and colum sums correspond to production values in input-output analysis, as they sum the total number of sectoral moves. In- and outflows correspond to final consumption components. Worker inflows or vacancies respectively are 'used up' in the process of regional labour market flows and terminate chains. Contrary job-to-job 'movers' parallel the intermediate input in the analysis of production.

${ }^{19}$ These conditions are: 1 . Homogeneity with respect to strata: each element of one stratum should have the same probability of moving to another stratum as all other elements of the same stratum; 2. Stationarity: Probabilities should be stable over time, 3. Markovicity: implies a memoryless moving pattern.

${ }^{20} \mathrm{~A}$ referee pointed out that this was a vague estimation of probabilites. In future research, a more microfounded estimation of these probability on the individual worker data could add further insights.
} 
matrix $N^{T}$ is divided by the respective row sum $s^{21}$ of the table.

$$
T=N^{T}\left(s^{-1}\right) d g
$$

Solving for $s$ in equation 3 results in the Leontief multiplier in equation 5: Each exogenous change of absorbtions $f$ results in a proportional change of job opportunities.

$$
s=(I-T)^{-1} f=L f
$$

The elements $l_{i j}$ of the Leontief multiplier $(1-T)^{-1}$ give the expected fraction of vacancy transfers from industry $i$ per new entrant in industry $j$. It is thereby also considering all implied indirect moves. This multiplier effect is the working horse of any subsequent analysis and can be used to simulate the vector of net new workplaces which is needed in order to ensure the absorption $=$ employment of an exogenous number of new entrants $f$.

This paper however will not go further in simulating new jobs needed, but instead concentrate on exploratively analyzing the 9 empirically calculated Leontief multipliers by means of a linkage analysis. With this analysis the 'role' of various industries in the 'whole' regional labour market as far as their connections via worker flows is concerned should be made transparent.

$$
\begin{aligned}
T B L_{j} & =\sum_{i=1}^{n} l_{i j} \\
T F L_{i} & =\sum_{j=1}^{n} l_{i j}
\end{aligned}
$$

Equation 6 calculates the total (direct and indirect) backward linkages $(T B L)$ as the colum sums of the Leontief inverse and gives the respective industry's $j$ dependency of receiving vacancies from other industries $i$ when external shocks occur in industry $j^{22}$. Equation 7 refers to industry $i$ 's total forward linkage (TFL) of vacancies and gives the industry's downstream linkage in sending vacancies ${ }^{23}$ to other industries $j$ when all industries are affected by external shocks. In order to reduce the vast information content of these linkage plots a classification scheme of combined $T B L$ and $T F L$ as suggested by Isard, Azis, Drennan, Miller, Saltzman and Thorbecke (1998) will be used. Combined measures are calculated by relating the industry-wise $T B L_{j}$ and $T F L_{i}$ to the average regional $T B L$ and $T F L$ across all industries.

\footnotetext{
${ }^{21}$ The vector of row sums $s$ is diagonalized into the matrix $s_{d g}$. Multiplication of the transfer matrix with the inverted diagonalized row sum matrix yields the required division.

${ }^{22}$ From the worker flow perspective the $T B L$ can be interpreted as the industry's downstream linkage in sending workers to other industries.

${ }^{23}$ Or receiving workers from other industries, respectively.
} 


$$
\begin{aligned}
& T B L *_{j}=T B L_{j} /[1 / n] \sum_{j=1}^{n} T B L_{j} \\
& T F L *_{i}=T F L_{i} /[1 / n] \sum_{i=1}^{n} T F L_{i}
\end{aligned}
$$

A value of $T B(F) L *_{j(i)}>1$ indicates that the respective industry shows higher than regional average back- or forward linkages. By plotting these $T B(F) L_{j(i)} *$ numbers in a 4-field diagram, four types of regional industries can be identified as depicted in figure 2. Key industries with both above average forward and backward linkages are assembled in field A. These industries exert high influence on others upon the occurance of external shocks to them and are also highly influenced by developments in other industries. Field B assembles those industries which are directly and indirectly receiving many vacancies from other industries upon own sector shocks, but in case of aggregate shocks sending only few vacancies and therefore denoted as 'vacancy absorbing industries'. Field C gathers all those industries which remain relatively isolated, while in field D those industries are collected which are highly vacancy emitting upon external shocks on the whole labour market.

Figure 2: Plot of Combined Linkages, Vacancy Perspective

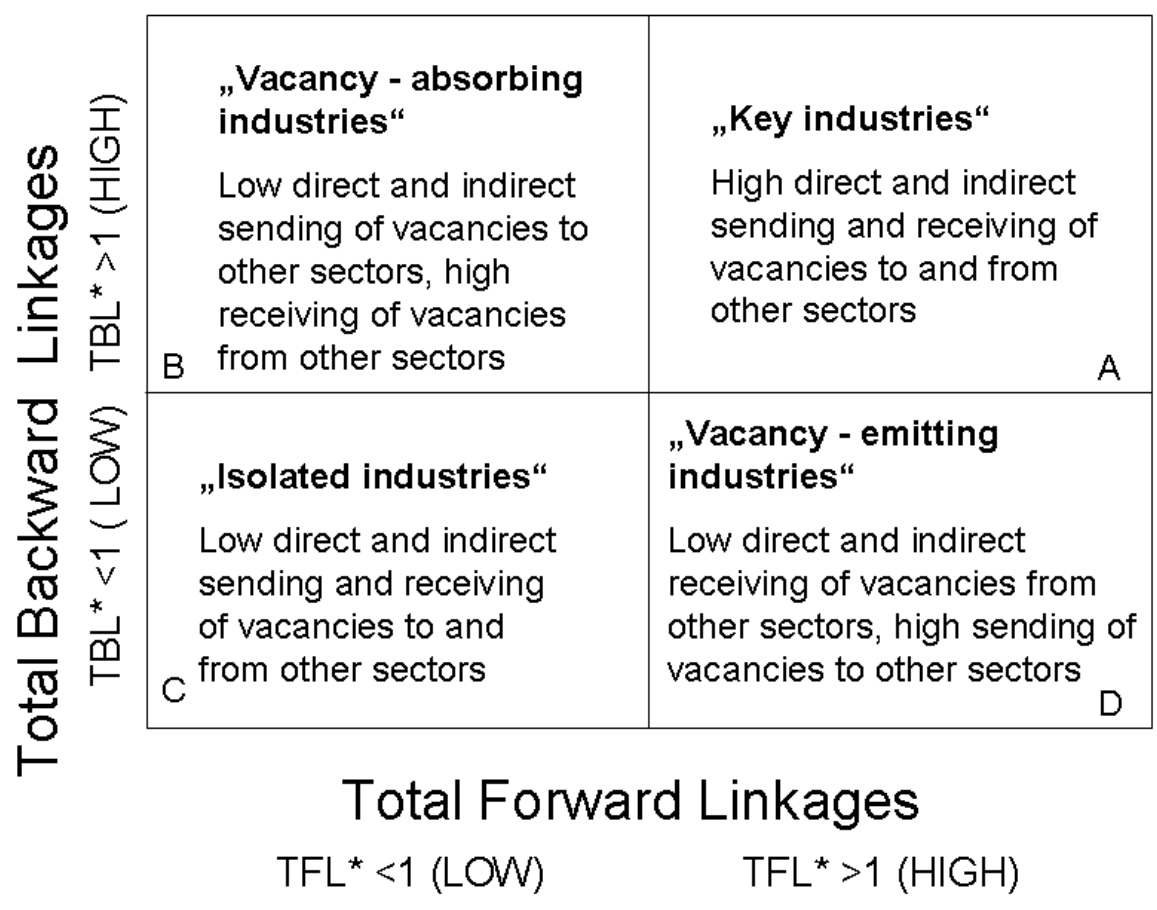


AUMAYR Inter- and intraindustrial Job-to-Job Flows

\section{Linkage Analysis of Vacancy Chain Leontief Multipliers}

Having established 9 separate regional vacancy chain tables of worker/vacancy flows for the year 2004 as described in section 4, this paper will continue with an empirical analysis of regional chain multipliers namely a linkage-analysis as suggested by Isard et al. (1998). For each Bundesland, the Leontief multiplier matrix is calculated as the inverse of the matrix of transfer probabilities $(I-T)^{-1}$ as denoted in equation 5. The resulting regional Leontief-multiplier matrices are depicted in figure 3 as sum across rows $(T B L)$ and in figure 4 as sum across columns $(T F L)$ for three selected regions. These regions have not been chosen randomly: Styria is an industry dominated region, Tyrol is a touristic region and Vienna as the capital region obtains high employment rates in all service categories. Tables 4 and 5 in the appendix give the absolute values of the linkage measures for each region.

TBL range between 1 (Burgenland X6162) and 2.69 (Vienna X7374), which means that an additional inflow of one person in Vienna's business service sector (X7374) would directly and indirectly involve 2.69 matched vacancies in total, whereas the same inflow in the Burgenland water and air transport industry (X6162) would only show the direct effect. Business services generally exhibit the highest $T B L$ in all regions - compare figure 3 and table 4. $T F L$ on the other hand range from 1 (Salzburg X19) to 3.04 (Vienna X7374): An additional inflow of 1 person in all of the 33 industries would not affect Salzburg's manufacture of leather and leather products (X19) indirectly, but generate in total 3.04 matched vacancies in the Vienna business service sector.

$T B L$ are generally lower than $T F L$ : From the plots in figure 3 and 4 it can be seen that the main effects are intraindustrial linkages. These are more likely to occur than interindustrial E-E moves and result in the chains remaining in the industry of initiation. This pattern is expected to decrease when allowing for a longer period of time during which E-E moves are counted in the transfer matrix. Industries with higher inter-industry forward multiplier effects are construction (X45), wholesale and retail (X5052), accomodation and food service activities (X55) as well as business services (X7374). Longer chains can generally be expected to start in service industries. While the level of all the other industries is slightly above 1 with negligible inter-industry effects in all regions, regions are heterogenous with respect to $T F L$ in these five sectors. In the industry dominated regions of Upper Austria, Styria and in Vienna business services (X7374) show much higher $T F L$ than the other industries ${ }^{24}$, while in the remaining Bundeslaender wholesale and retail (X5052) is by far the industry with the highest TFL. Tourism-oriented regions such as Salzburg, Tirol and Carinthia together with Vienna, furthermore, show higher $T F L$ in tourism (X55) than the other regions.

The 4-field plots depicted in Figure 5 on page 100 reveal the following 'general' industrywise linkage pattern over all nine regions.

\footnotetext{
${ }^{24}$ This finding can be attributed to temporary work agencies being classified in the business service indus-
} 
Figure 3: Leontief Multiplier for the Austrian Bundeslaender depicted as Sum across Rows $=$ Industrial Direct and Indirect Backward Linkages
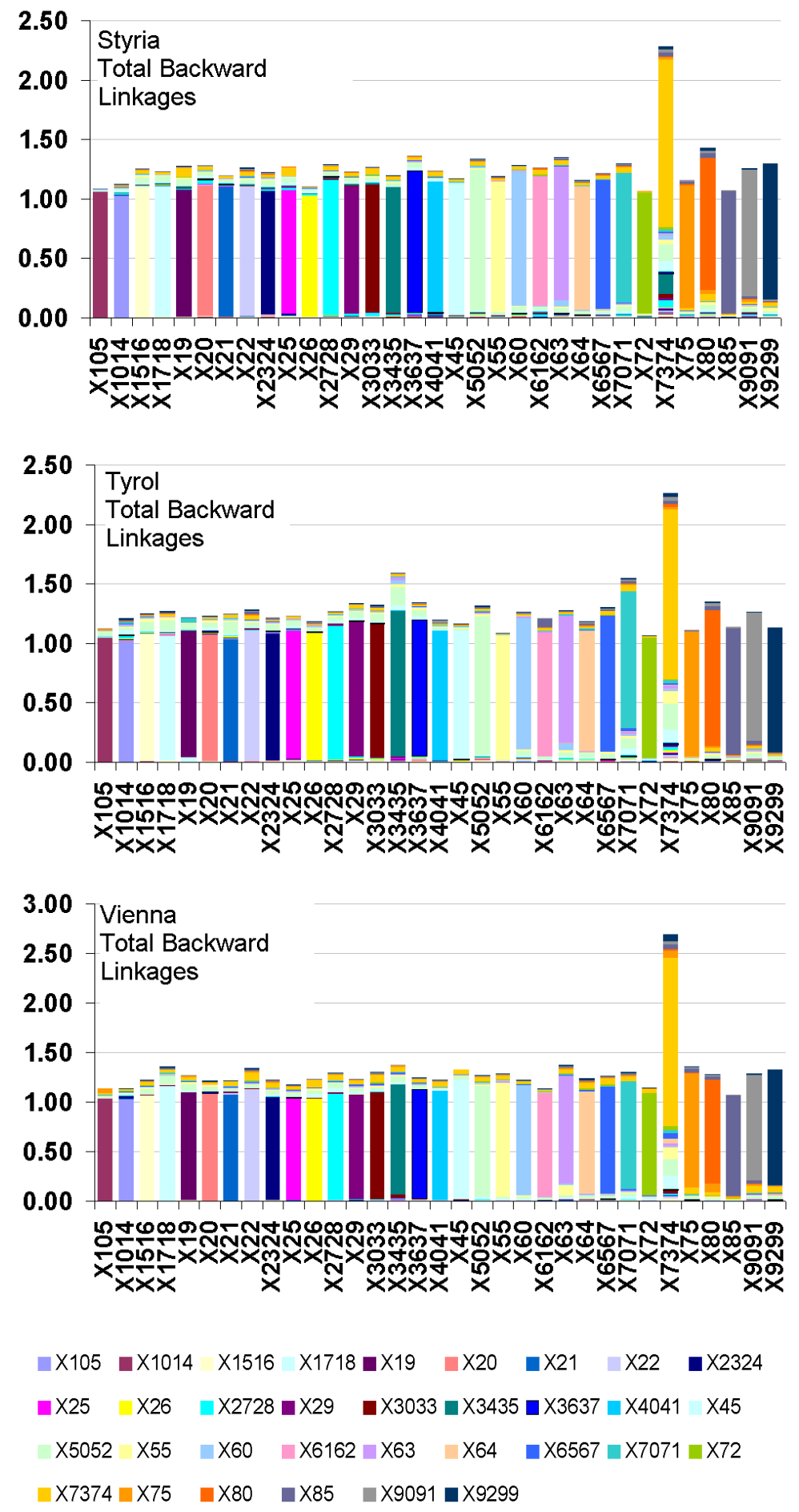
AUMAYR Inter- and intraindustrial Job-to-Job Flows

Figure 4: Leontief Multiplier for the Austrian Bundeslaender depicted as Sum across Columns $=$ Industry-wise Direct and Indirect Forward Linkages
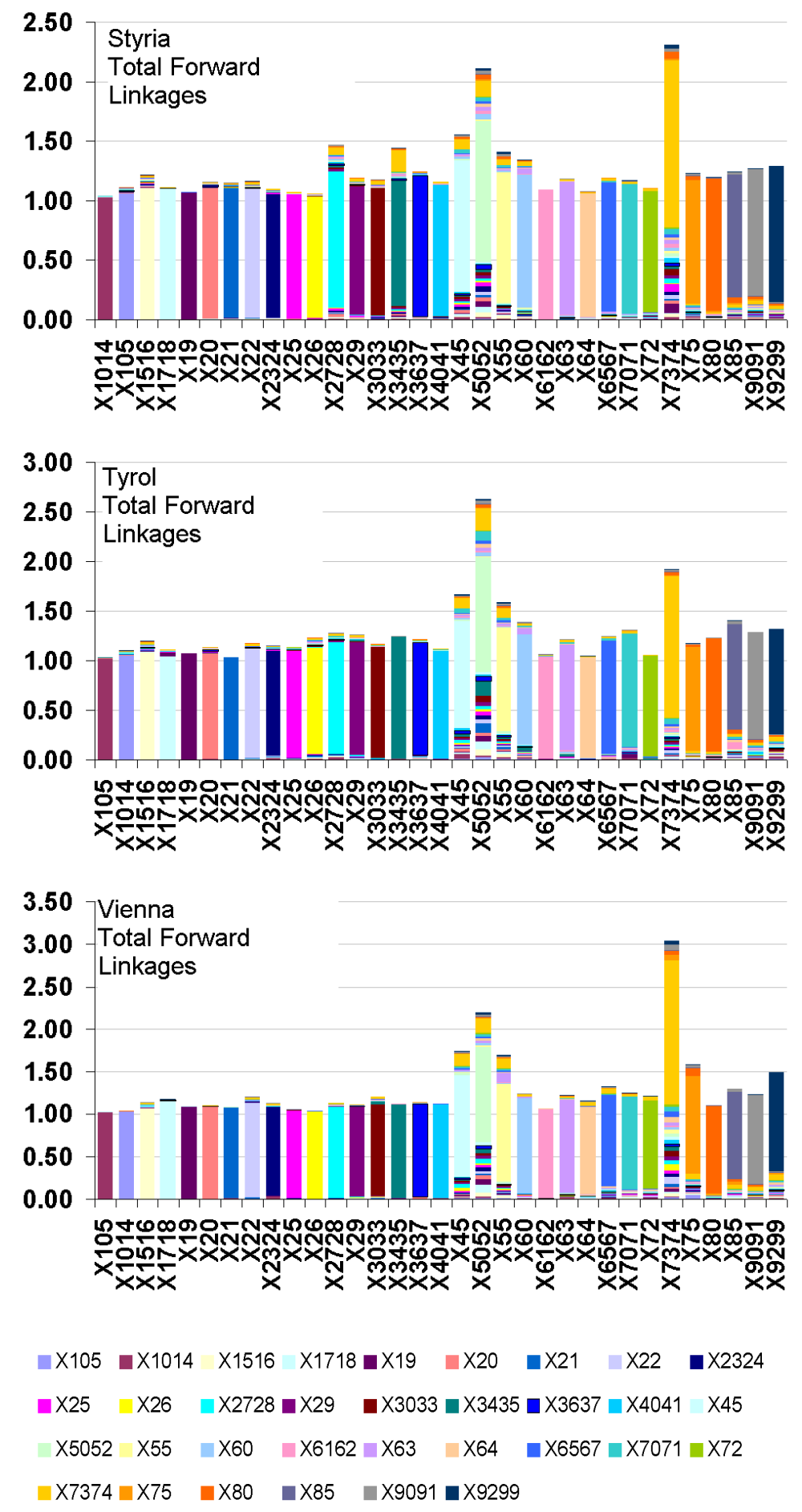
Figure 5: Industry-wise Results of the Combined Linkage Analysis. In Brackets: Number of Regional Industries in the Respective Fields. Bold: Majority of Regional Industries in the Respective Field.

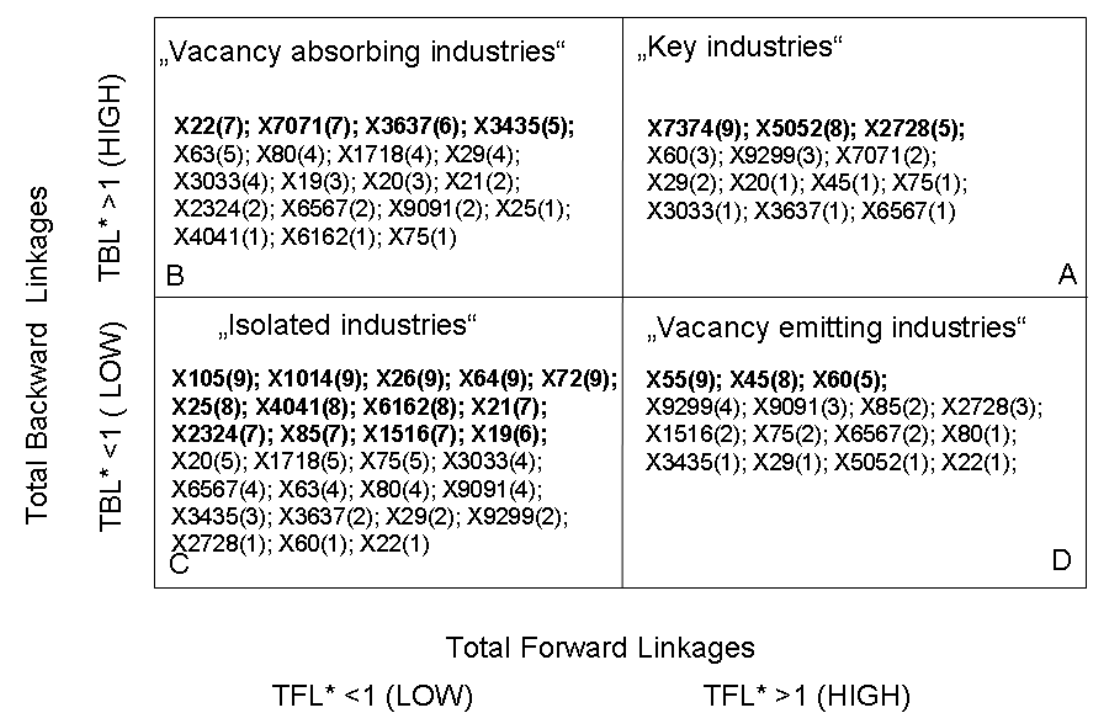

- A Key industries: in almost all cases ${ }^{25}$ business services (X7374) and wholesale and retail (X5052) are classified as key sectors with respect to receiving and forwarding vacancies. Additionally in five out of nine regions the manufacture of basic metals and fabricated metal products (X2728) can be denoted a key sector in for- and backwarding labour market dynamics.

- B Vacancy absorbing industries: As vacancy absorbing industries publishing, printing and the reproduction of recorded media (X22), real estate and renting activities (X7071), manufacture of furniture and recycling (X3637) and transport equipment (X3435) were identified in most of the regions. Additional inflows of workers in these industries will result in immediately handing workers over to other industries, while upon inflows in other industries, only low impacts will be generated on B-type industries.

- C Isolated industries: The majority of industries is isolated with lower than average total forward and backward linkages. In these mainly intraindustry labour market effects can be found upon external shocks.

- D Vacancy emitting industries: Construction (X45), hotels and restaurants ('tourism') (X55) and transport (X60) are in most regional cases vacancy-emitting (or labour-absorbing)

try. These have tight linkages with many manufacturing industries.

${ }^{25}$ Only in Vienna wholesale and retail is a vacancy emitting industry. 
AUMAYR Inter- and intraindustrial Job-to-Job Flows

industries with high forward linkages of vacancies. The high seasonal dynamics of the first two makes them important in generating vacancy chains in the regional labour market. External shocks to them show a low impact on others, whereas upon aggregate external shocks, labour will be absorbed in these industries and further vacancies created in other industries.

\section{Summary and Conclusion}

Job-to-job flows are a main driver of regional labour market dynamics through unfolding impacts not only in those industries subject to external shocks, but also in other interlinked industries via 'vacancy chains' of worker mobility. Here, these flows were represented in an Input-Output framework. Based on a rich dataset which allows for the career tracing of all Austrian insured and co-insured persons, 9 regional NUTS 2 year 2004 vacancy chain tables were constructed, tracing aggregate regional worker or vacancy moves between 33 industries. The row and column sums of the Leontief multiplier were interpreted as the respective industry's ability of actively sending or passively receiving vacancies and henceforth are an indicator of industrial for- and backward linkages or their 'role' in the regional labour market system. The length of the industrial multiplier (TBL) can be taken to count for net gains, when weighted with wage differentials. This, however, still remains to be done.

From these efforts, the following points summarize the main empiricical findings: Interindustrial flows are generally lower than intra-industrial E-E flows. Multipliers range up to 2.7 (in business services), while in most cases the industrial multipliers lie below 1.3. These observations are expected to decrease when allowing for a longer time span with some frictional non-employment during which job-to-job moves are still counted in the transfer matrix. According to the linkage analysis of industrial vacancies, only 2-3 industries can be termed national 'key' industries which influence others by sending vacancies and are influenced by others through receiving vacancies. These industries are business services, wholesale and retail and in 5 out of 9 regions also the metal industry. Construction and tourism are 'vacancy emitting'. It will be necessary to keep an eye on these and the former mentioned 'key' industries when it comes to forcasting or analyzing impacts on other industries. As rather 'passive' or 'vacancy absorbing' industries publishing and printing, real estate and renting activities, the manufacture of furniture and of transport equipment were identified in most of the regions. Apart from these 'nationwide' findings, there is regional heterogeneity with respect to the above mentioned classification: industry dominated regions show much higher backward linkages of business services than tourism-oriented regions do.

What is the value added for labour market policies? The classification of industrial workerflow linkages obtained can be utilized as qualitative (or quantitative) information e.g. in employment forecasts or impact evaluation studies: The projected development of those industries

with high active sums can be an additional input in forecasting the development of other indus- 
tries. Knowledge of these inter- and intraindustrial labour market linkages has a high policy relevance. Labour market institutions such as the Public Employment Service (PES) engaged with manpower planning and medium-term (re-)qualification tasks, can make use of the observed interindustrial linkages in their programme design. Regional development authorities could utilize ex ante evalution results on the nature of these vertical labour market multipliers as additional input in their decision schedules between different industrial promotion programmes. Particularly when 'trickle down' effects are expected and argued, the quantification of these can be a valuable input in the decision process among different industrial promotion programmes. Further analytical and policy relevant interests could lie in the question whether and which regional clusters are formed via these observed labour market linkages and the implied knowledge spillovers.

Future perspectives for research in this area include the check for the robustness of the results as far as the temporal stability of worker or vacancy flows, the industrial aggregation and the utilization of the model for simulation exercises of industrial job-need assessments are concerned. It is furthermore envisaged to connect these multipliers with individual wage data in order to calculate flows could be generated. Beside these purely 'mechanistic' views of interlinkages, the study on the micro-determinants of interindustrial worker flows opens wide ranging gates of research, valuable for policy-makers engaged with structural mismatches on labour markets.

\section{Appendix}

Table 1: List of Abbreviations

\begin{tabular}{ll}
\hline \hline Abbreviation & Term \\
\hline \hline AMS (PES) & Public Employment Service, Austria \\
BMASK & Federal Ministry of Labour, Social Affairs and Con- \\
& sumer Protection \\
BMWA & Ministry for Economy and Labour (until end of 2008) \\
E-E & Employment-to-employment worker flows \\
HVSV & Main Association of the Austrian Health Insurances \\
LMDB & Labour Market Database \\
NUTS & Nomenclature of Territorial Units for Statistics \\
OENACE & Austrian classification of economic activities \\
TBL & Total Backward Linkage \\
OLF & Out of Labour Force \\
TFL & Total Foreward Linkage \\
VCA & Vacancy Chain Approach \\
\hline \hline
\end{tabular}


AUMAYR Inter- and intraindustrial Job-to-Job Flows

Table 2: Labour Market States in the LMDB and their Dominance when Multiple States are Registered.

\begin{tabular}{ll}
\hline \hline First level & Second Level \\
\hline \hline Dependent employment & Fragmented employment \\
\hline Unemployment & Registered unemployment \\
& Participants in ALMP: Training etc. \\
\hline Dependent employment & Participants in ALMP: Subsidized employment \\
& Civil servants \\
& Trainees in apprenticeships \\
& Blue and white collar workers \\
& Freelancers \\
& Other dependent employment \\
\hline Self-employment & Farmers incl. helping family members \\
& Self-employed \\
& Other self-employed and contracts of work and labour \\
\hline Secure OLF states & Maternity allowance with ongoing employment contract \\
& Maternity allowance without ongoing employment contract \\
& Parents allowance with ongoing employment contract \\
& Parents allowance without ongoing employment contract \\
& Child care benefit with ongoing employment contract \\
& Child care benefit without ongoing employment contract \\
& Military service and alternative civilian service \\
& Pensions \\
\hline Very short time-employment contracts & Other secured OLF positions \\
& Very short time employment contracts \\
Other OLF states \& Education & Other insurance times (i.e. widow- and orphanage pay- \\
& ments) \\
\hline Other & Non-insurance episodes \\
\hline \hline & Birth \\
& Death \\
& No Data \\
\hline
\end{tabular}

Source: AMS, BMWA (2007) 
Review of Economic Analysis 2 (2010) 86-109

Table 3: 33-Industry Aggregation of OENACE 2-digit Industries by the Author.

\begin{tabular}{|c|c|c|}
\hline Industry & $\begin{array}{l}\text { OENACE } 2003 \\
\text { 2-digit }\end{array}$ & Name \\
\hline $\mathrm{X} 105$ & $01,02,05$ & Agriculture, hunting and forestry and fishery \\
\hline X1014 & $10,11,12,14$ & Mining and quarrying \\
\hline $\mathrm{X} 1516$ & 15,16 & Manufacturing of food products, beveredges and tobacco \\
\hline $\mathrm{X} 1718$ & 17,18 & Manufacturing of textiles and textile products \\
\hline $\mathrm{X} 19$ & 19 & Manufacture of leather and leather products \\
\hline $\mathrm{X} 20$ & 20 & Manufacture of wood and wood products \\
\hline $\mathrm{X} 21$ & 21 & Manufacture of pulp, paper and paper products \\
\hline $\mathrm{X} 22$ & 22 & Publishing, printing and the reproduction of recorded media \\
\hline $\mathrm{X} 2324$ & 23,24 & Manufacture of chemicals and chemical products and others \\
\hline $\mathrm{X} 25$ & 25 & Manufacture of rubber and plastic \\
\hline $\mathrm{X} 26$ & 26 & Manufacture of other non-metallic mineral products \\
\hline $\mathrm{X} 2728$ & 27,28 & Manufacture of basic metals and fabricated metal products \\
\hline $\mathrm{X} 29$ & 29 & Manufacture of machinery and equipment \\
\hline $\mathrm{X} 3033$ & $30,31,32,33$ & Manufacture of electrical and optical equipment \\
\hline $\mathrm{X} 3435$ & 34,35 & Manufacture of transport equipment \\
\hline $\mathrm{X} 3435$ & 34,35 & Manufacture of transport equipment \\
\hline $\mathrm{X} 3637$ & 36,37 & Manufacturing, N.E.C. \\
\hline $\mathrm{X} 4041$ & 40,41 & Electricity, gas and water supply \\
\hline $\mathrm{X} 45$ & 45 & Construction \\
\hline $\mathrm{X} 5052$ & $50,51,52$ & Wholesale and retail trade; \\
\hline $\mathrm{X} 55$ & 55 & Hotels and restaurants \\
\hline X60 & 60 & Land transport and transport in Pipelines \\
\hline $\mathrm{X} 6162$ & 61,62 & Water and air transport \\
\hline X63 & 63 & $\begin{array}{l}\text { Supporting and auxiliary transport activities; activities of travel } \\
\text { agencies }\end{array}$ \\
\hline X64 & 64 & Post and telecommunications \\
\hline X6567 & $65,66,67$ & Financial intermediation \\
\hline $\mathrm{X} 7071$ & 70,71 & Real estate and renting activities \\
\hline $\mathrm{X} 72$ & 72 & Computer and related activities \\
\hline $\mathrm{X} 7374$ & 73,74 & R\&D and other business activities ('business services') \\
\hline $\mathrm{X} 75$ & 75 & Public administraton and defence; compulsory social security \\
\hline $\mathrm{X} 80$ & 80 & Education \\
\hline $\mathrm{X} 85$ & 85 & Health and social work \\
\hline X9091 & 90,91 & Sewage and refuse disposal, sanitation and similar activities; \\
\hline X9299 & $\begin{array}{l}92,93,95,96 \\
97,99\end{array}$ & Recreational, cultural and sporting and other service activities etc; \\
\hline
\end{tabular}

Source: Statistic Austria 
AUMAYR Inter- and intraindustrial Job-to-Job Flows

Table 4: Total Backward Linkages by Industries and Regions.

\begin{tabular}{|c|c|c|c|c|c|c|c|c|c|}
\hline NACE & $\begin{array}{l}\text { Burgen- } \\
\text { land }\end{array}$ & Carinthia & $\begin{array}{l}\text { Lower } \\
\text { Austria }\end{array}$ & $\begin{array}{l}\text { Upper } \\
\text { Austria }\end{array}$ & Salzburg & Styria & Tyrol & $\begin{array}{l}\text { Vorarl- } \\
\text { berg }\end{array}$ & Vienna \\
\hline X105 & 1.09 & 1.09 & 1.08 & 1.15 & 1.12 & 1.08 & 1.13 & 1.17 & 1.14 \\
\hline X1014 & 1.11 & 1.12 & 1.17 & 1.19 & 1.10 & 1.13 & 1.21 & 1.25 & 1.13 \\
\hline X1516 & 1.17 & 1.25 & 1.18 & 1.31 & 1.24 & 1.26 & 1.25 & 1.20 & 1.22 \\
\hline X1718 & 1.14 & 1.28 & 1.21 & 1.21 & 1.30 & 1.23 & 1.27 & 1.30 & 1.36 \\
\hline X19 & 1.10 & 1.35 & 1.20 & 1.36 & 1.11 & 1.28 & 1.22 & 1.27 & 1.27 \\
\hline X20 & 1.09 & 1.18 & 1.28 & 1.23 & 1.25 & 1.29 & 1.23 & 1.42 & 1.22 \\
\hline $\mathrm{X} 21$ & 1.27 & 1.33 & 1.22 & 1.18 & 1.12 & 1.20 & 1.25 & 1.27 & 1.21 \\
\hline $\mathrm{X} 22$ & 1.29 & 1.29 & 1.54 & 1.37 & 1.33 & 1.26 & 1.29 & 1.26 & 1.34 \\
\hline X2324 & 1.20 & 1.18 & 1.14 & 1.29 & 1.17 & 1.23 & 1.22 & 1.39 & 1.22 \\
\hline $\mathrm{X} 25$ & 1.10 & 1.20 & 1.19 & 1.33 & 1.15 & 1.28 & 1.23 & 1.22 & 1.18 \\
\hline $\mathrm{X} 26$ & 1.04 & 1.14 & 1.14 & 1.26 & 1.16 & 1.10 & 1.18 & 1.22 & 1.23 \\
\hline X2728 & 1.18 & 1.28 & 1.22 & 1.35 & 1.26 & 1.29 & 1.27 & 1.19 & 1.29 \\
\hline X29 & 1.09 & 1.57 & 1.24 & 1.33 & 1.34 & 1.23 & 1.34 & 1.29 & 1.24 \\
\hline X3033 & 1.22 & 1.18 & 1.19 & 1.37 & 1.21 & 1.27 & 1.32 & 1.26 & 1.30 \\
\hline X3435 & 2.36 & 1.25 & 1.19 & 1.23 & 1.22 & 1.2 & 1.60 & 1.33 & 1.38 \\
\hline X3637 & 1.20 & 1.29 & 1.24 & 1.34 & 1.24 & 1.37 & 1.34 & 1.41 & 1.25 \\
\hline X4041 & 1.12 & 1.16 & 1.13 & 1.19 & 1.23 & 1.24 & 1.20 & 1.29 & 1.22 \\
\hline $\mathrm{X} 45$ & 1.14 & 1.14 & 1.14 & 1.21 & 1.16 & 1.17 & 1.16 & 1.24 & 1.33 \\
\hline X5052 & 1.21 & 1.30 & 1.23 & 1.35 & 1.31 & 1.33 & 1.31 & 1.32 & 1.27 \\
\hline X55 & 1.14 & 1.12 & 1.18 & 1.25 & 1.10 & 1.19 & 1.08 & 1.10 & 1.29 \\
\hline X60 & 1.14 & 1.24 & 1.19 & 1.30 & 1.25 & 1.29 & 1.26 & 1.30 & 1.22 \\
\hline X6162 & 1.00 & 1.19 & 1.15 & 1.42 & 1.21 & 1.26 & 1.21 & 1.05 & 1.13 \\
\hline X63 & 1.13 & 1.26 & 1.14 & 1.40 & 1.22 & 1.35 & 1.28 & 1.26 & 1.37 \\
\hline X64 & 1.09 & 1.15 & 1.11 & 1.18 & 1.16 & 1.16 & 1.18 & 1.16 & 1.25 \\
\hline X6567 & 1.17 & 1.19 & 1.17 & 1.30 & 1.28 & 1.22 & 1.30 & 1.32 & 1.26 \\
\hline X7071 & 1.29 & 1.41 & 1.39 & 1.37 & 1.57 & 1.3 & 1.55 & 1.34 & 1.31 \\
\hline $\mathrm{X} 72$ & 1.01 & 1.03 & 1.04 & 1.05 & 1.05 & 1.07 & 1.06 & 1.17 & 1.14 \\
\hline X7374 & 1.60 & 2.15 & 2.06 & 2.47 & 2.20 & 2.29 & 2.27 & 2.27 & 2.69 \\
\hline X75 & 1.07 & 1.18 & 1.12 & 1.58 & 1.22 & 1.16 & 1.12 & 1.08 & 1.36 \\
\hline X80 & 1.10 & 1.18 & 1.14 & 1.67 & 1.26 & 1.43 & 1.35 & 1.25 & 1.28 \\
\hline X85 & 1.10 & 1.08 & 1.09 & 1.06 & 1.04 & 1.07 & 1.14 & 1.08 & 1.07 \\
\hline X9091 & 1.14 & 1.29 & 1.33 & 1.26 & 1.21 & 1.25 & 1.26 & 1.28 & 1.29 \\
\hline X9299 & 1.23 & 1.23 & 1.21 & 1.31 & 1.14 & 1.30 & 1.14 & 1.20 & 1.33 \\
\hline
\end{tabular}

Source: Own Calculations 
Review of Economic Analysis 2 (2010) 86-109

Table 5: Total Forward Linkages by Industries and Regions.

\begin{tabular}{|c|c|c|c|c|c|c|c|c|c|}
\hline NACE & $\begin{array}{l}\text { Burgen- } \\
\text { land }\end{array}$ & Carinthia & $\begin{array}{l}\text { Lower } \\
\text { Austria }\end{array}$ & $\begin{array}{l}\text { Upper } \\
\text { Austria }\end{array}$ & Salzburg & Styria & Tyrol & $\begin{array}{l}\text { Vorarl- } \\
\text { berg }\end{array}$ & Vienna \\
\hline X105 & 1.13 & 1.11 & 1.10 & 1.14 & 1.09 & 1.12 & 1.10 & 1.13 & 1.03 \\
\hline X1014 & 1.07 & 1.06 & 1.03 & 1.06 & 1.04 & 1.04 & 1.04 & 1.01 & 1.03 \\
\hline X1516 & 1.15 & 1.19 & 1.23 & 1.32 & 1.19 & 1.22 & 1.20 & 1.33 & 1.14 \\
\hline X1718 & 1.12 & 1.09 & 1.14 & 1.11 & 1.14 & 1.12 & 1.11 & 1.20 & 1.17 \\
\hline X19 & 1.05 & 1.16 & 1.11 & 1.12 & 1.00 & 1.07 & 1.07 & 1.07 & 1.09 \\
\hline X20 & 1.11 & 1.15 & 1.27 & 1.14 & 1.18 & 1.16 & 1.14 & 1.15 & 1.10 \\
\hline X21 & 1.13 & 1.24 & 1.17 & 1.11 & 1.08 & 1.15 & 1.03 & 1.13 & 1.08 \\
\hline X22 & 1.15 & 1.19 & 1.45 & 1.17 & 1.14 & 1.16 & 1.18 & 1.23 & 1.20 \\
\hline X2324 & 1.06 & 1.09 & 1.14 & 1.16 & 1.07 & 1.10 & 1.15 & 1.09 & 1.13 \\
\hline X25 & 1.11 & 1.13 & 1.13 & 1.21 & 1.09 & 1.07 & 1.13 & 1.15 & 1.05 \\
\hline X26 & 1.05 & 1.11 & 1.10 & 1.14 & 1.06 & 1.06 & 1.23 & 1.12 & 1.04 \\
\hline X2728 & 1.21 & 1.26 & 1.34 & 1.56 & 1.25 & 1.47 & 1.28 & 1.60 & 1.14 \\
\hline X29 & 1.06 & 1.52 & 1.26 & 1.37 & 1.22 & 1.19 & 1.26 & 1.26 & 1.12 \\
\hline X3033 & 1.65 & 1.19 & 1.13 & 1.22 & 1.15 & 1.17 & 1.17 & 1.26 & 1.21 \\
\hline X3435 & 1.11 & 1.21 & 1.09 & 1.19 & 1.15 & 1.45 & 1.25 & 1.17 & 1.13 \\
\hline X3637 & 1.10 & 1.23 & 1.16 & 1.28 & 1.19 & 1.25 & 1.22 & 1.37 & 1.14 \\
\hline X4041 & 1.17 & 1.12 & 1.05 & 1.17 & 1.08 & 1.16 & 1.12 & 1.19 & 1.13 \\
\hline X45 & 1.85 & 1.66 & 1.45 & 1.54 & 1.47 & 1.56 & 1.67 & 1.73 & 1.74 \\
\hline X5052 & 1.69 & 2.04 & 1.95 & 2.34 & 2.43 & 2.11 & 2.63 & 2.33 & 2.19 \\
\hline X55 & 1.31 & 1.39 & 1.28 & 1.48 & 1.61 & 1.41 & 1.59 & 1.43 & 1.69 \\
\hline X60 & 1.25 & 1.31 & 1.27 & 1.41 & 1.31 & 1.34 & 1.39 & 1.53 & 1.24 \\
\hline X6162 & 1.01 & 1.09 & 1.13 & 1.06 & 1.02 & 1.09 & 1.07 & 1.02 & 1.07 \\
\hline X63 & 1.04 & 1.14 & 1.14 & 1.30 & 1.17 & 1.18 & 1.22 & 1.09 & 1.22 \\
\hline X64 & 1.10 & 1.05 & 1.06 & 1.09 & 1.04 & 1.08 & 1.05 & 1.06 & 1.16 \\
\hline X6567 & 1.15 & 1.17 & 1.14 & 1.24 & 1.26 & 1.20 & 1.25 & 1.29 & 1.32 \\
\hline X7071 & 1.15 & 1.18 & 1.16 & 1.20 & 1.28 & 1.17 & 1.31 & 1.14 & 1.25 \\
\hline X72 & 1.02 & 1.05 & 1.06 & 1.10 & 1.06 & 1.11 & 1.06 & 1.09 & 1.22 \\
\hline X7374 & 1.55 & 1.96 & 1.80 & 2.74 & 2.19 & 2.31 & 1.93 & 2.12 & 3.04 \\
\hline X75 & 1.09 & 1.30 & 1.18 & 1.83 & 1.20 & 1.23 & 1.18 & 1.08 & 1.59 \\
\hline X80 & 1.08 & 1.10 & 1.08 & 1.33 & 1.18 & 1.20 & 1.23 & 1.13 & 1.11 \\
\hline X85 & 1.14 & 1.23 & 1.19 & 1.26 & 1.19 & 1.25 & 1.40 & 1.27 & 1.30 \\
\hline X9091 & 1.13 & 1.25 & 1.23 & 1.22 & 1.16 & 1.27 & 1.29 & 1.13 & 1.24 \\
\hline X9299 & 1.36 & 1.29 & 1.22 & 1.30 & 1.25 & 1.29 & 1.31 & 1.23 & 1.49 \\
\hline
\end{tabular}

Source: Own Calculations 
AUMAYR Inter- and intraindustrial Job-to-Job Flows

\section{References}

Akerlof, G. A., Rose, A. K. and Yellen, J. L. (1988), Job Switching and Job Satisfaction in the U.S. Labor Market, Brookings Papers on Economic Activity, 495-594.

AMS and BMWA (2007), Beschreibung der Wuerfel der AMS-BMWA Arbeitsmarktdatenbank, Technical report, PES Austria (AMS) and BMWA.

Anselin, L. (1988), Spatial Econometrics: Models and Methods, Dorddrecht: Kluwer Academic Publishers.

Blanchard, O. J. and Diamond, P. (1990), The Cyclical Behaviour of Gross Flows of U.S. workers, Brookings Papers on Economic Activity, 85-143.

Blanchard, O. J. and Diamond, P. (1992), The Flow Approach to Labor Markets, American Economic Review 82, 354-59.

Blum, Y., Roth, A. E. and Rothblum, U. G. (1997), Vacancy Chains and Equilibration in SeniorLevel Labor Markets, Journal of Economic Theory 76, 362-411.

Boeckerman, P., Haemaelaeinen, K. and Maliranta, M. (2002), Sources of Job and Worker Flows: Evidence from a Panel of Regions, MPRA Paper 4887, University Library of Munich, Germany.

Burgess, S., Lane, J. and Stevens, D. (1995), Job Flows, Worker Flows and Churning, CEPR Discussion Papers 1125.

Burgess, S., Lane, J. and Stevens, D. (2000), Job Flows, Worker Flows, and Churning, Journal of Labor Economics 18, 473-502.

Burgess, S., Lane, J. and Stevens, D. (2001), Churning Dynamics: an Analysis of Hires and Separations at the Employer Level, Labour Economics 8, 1-14.

Butter, F. A. D. and van Dijk, M. (1998), The Pace of Job Creation and Destruction, Cyclical Shocks and Employment Dynamics, Labour 12, 613-632.

Chase, I. (1991), Vacancy Chains, Annual Review of Sociology 17, 133-154.

Chase, I., Weissburg, M. and Dewitt, T. (1988), The Vacancy Chain Process: a New Mechanism of Resource Distribution in Animals with Application to Hermit Crabs, Animal behaviour 36, 1265-1274.

Contini, B. and Revelli, R. (1987), The Process of Job Creation and Job Destruction in the Italian Economy, Labour 1, 121-144.

Contini, B. and Revelli, R. (1997), Gross Flows vs. Net Flows in the Labor Market: What is there to be Learned?, Labour Economics 4, 245-263.

Davis, S. and Haltiwanger, J. (1989), Gross Job Creation, Gross Job Destruction And Employment Reallocation, Papers e-89-33, Stanford - Hoover Institution.

Davis, S. J. and Haltiwanger, J. C. (1992), Gross Job Creation, Gross Job Destruction, and Employment Reallocation, The Quarterly Journal of Economics 107, 819-63.

Decressin, J. and Fatas, A. (1995), Regional Labor Market Dynamics in Europe, European Economic Review 39, 1627-1655. 
Eberts, R. W. and Montgomery, E. (1995), Cyclical versus Secular Movements in Employment Creation and Destruction, NBER Working Papers 5162.

Emmi, P. C. (1984), Primal/dual Relationships in a Pair of Multi-sectoral Housing Market Models, Journal of Regional Science 24, 17-34.

Emmi, P. C. (1985), Modelling Interoccupational Relations in a Regional Labor Market, Papers in Regional Science 57, 125-138.

Emmi, P. C. (1986), The role of Interoccupational Relations in Regional Economic Development, Socio-Economic Planning Sciences 20, 41-49.

Emmi, P. C. and Magnusson, L. (1993), Intrasectoral Homogeneity and the Accuracy of Multisectoral Models, The Annals of Regional Science 27, 343-62.

Emmi, P. C. and Magnusson, L. (1994), The Predictive Accuracy of Residential Vacancy Chain Models, Urban Studies 31, 1117-1131.

Emmi, P. C. and Magnusson, L. (1995), Opportunities and Mobility in Urban Housing Markets: Concepts, Models, Calibrations and Tests, Progress in Planning 43, 1-88.

Eriksson, T. and Pehkonen, J. (1998), Unemployment Flows in Finland, 1969-95: A Time Series Analysis, Labour 12, 571-593.

Felsenstein, D. and Persky, J. (2006), Job Vacancy Chains and Local Employment Creation; the Case of Supply-Side Restrictions, ERSA conference papers 82, European Regional Science Association.

Felsenstein, D., Persky, J. and Carlson, V. (2002), Job Vacancy Chains in Metropolitan Labor Markets, ERSA conference papers 88, European Regional Science Association.

Garibaldi, P. (2000), Job Flows and Plant Size Dynamics: Traditional Measures and Alternative Econometric Techniques, Labour 14, 185-212.

Gautier, P. and Broersma, L. (2001), The Timing of Labour Reallocation and the Business Cycle: Evidence for The Netherlands, Labour 15, 663-684.

Gomez-Salvador, R., Messina, J. and Vallanti, G. (2004), Gross Job Flows and Institutions in Europe, Labour Economics 11, 469-485.

Isard, W., Azis, I., Drennan, M., Miller, R., Saltzman, S. and Thorbecke, E. (1998), Methods of Interregional and Regional Analysis, Ashgate.

Moen, J. (2004), When Subsidized R\&D-firms Fail, Do They Still Stimulate Growth? Tracing Knowledge by Following Employees Across Firms, Discussion Papers 399, Research Department of Statistics, Norway.

Moen, J. (2005), Is Mobility of Technical Personnel a Source of R\&D Spillovers?, Journal of Labour Economics 23, 81-114.

Mortensen, D. and Pissarides, C. (1992), The Cyclical Behavior of Job Creation and Job Destruction, Discussion Papers 982, Northwestern University, Center for Mathematical Studies in Economics and Management Science. 
AUMAYR Inter- and intraindustrial Job-to-Job Flows

Mortensen, D. T. and Pissarides, C. A. (1994), Job Creation and Job Destruction in the Theory of Unemployment, Review of Economic Studies 61, 397-415.

Persky, J. and Felsenstein, D. (2008), Multipliers, Markups, and Mobility Rents: in Defense of 'Chain models' in Urban and Regional Analysis, Environment and Planning A 40, 29332947.

Persky, J., Felsenstein, D. and Carlson, V. (2004), Does 'Trickle Down' Work? Economic Development Strategies and Job Chains in Local Labor Markets, W.E. Upjohn Institute for Employment Research.

Pinfield (1997), The Operation of Internal Labor Markets: Staffing Practices and Vacancy Chains, Contemporary Sociology 26, 372-373.

Pissarides, C. (2000), Equilibrium Unemployment Theory, 2nd edition, The MIT Press.

Shankar, K. and Ghosh, S. (2005), Favorable Selection in the Labor Market: A Theory of Worker Mobility in R\&D Intensive Industries, Working Papers 05006, Department of Economics, College of Business, Florida Atlantic University.

White, H. (1970a), Chains of opportunity: System Models of Mobility in Organizations, Harvard Universtity Press.

White, H. (1970b), Matching, Vacancies, and Mobility, The Journal of Political Economy 78, 97-105.

White, H. (1971), Multipliers, Vacancy Chains and Filtering in Housing, Journal of the American Planning Association 37, 88-94. 